\section{Rich Man, Poor Man}

By John Hilton. Sir Halley Stewart Lectures, I939. With a Foreword by Sir William Beveridge. Size: Cr. 8vo. Price: about 7s. 6d. Publisher: George Allen \& Unwin, Ltd.

“. .. examines the facts as to the distribution of wealth in this country.... The book tells of a special study of three hundred poor families, and goes on to examine various aspects of our spending, and discusses what it all means in terms of national well-being and strength, and what to do about it."

\section{The Pillars of Society and Other War-Time Essays and Addresses}

by Sir William Beveridge, with Cartoons by Low. Size: Cr. 8vo. Price: 6s. Publisher: George Allen \& Unwin Ltd.

\section{Social Security}

Edited by Dr. W. A. Robson. 2nd Edition. Size: Demy 8vo. Price: I5s. Publisher: George Allen \& Unwin, Ltd.

\section{Psychology and the Soldier}

The Art of Leadership. By Norman Copel.and. Size: Cr. 8vo. Price: 5s. Publisher: George Allen \& Unwin, Ltd.

“. . The author summarises the importance of morale and the psychology behind it, both to soldiers and civilians .... he proceeds to analyse the elements which contribute to that all-important 'attitude of mind." "

\section{The Biology of Flight}

By Frederick L. Fitzpatrick and Karl A. Stiles. Size: Demy 8vo. Illustrated. Price: about 8s. 6d. Publisher: George Allen \& Unwin, Ltd.

“. . . Begins with the origin of flight among insects and winged reptiles, and the nature of flight in the animal world. Proceeding to man, there follows a survey of the effects of altitude and the measures designed to withstand these effects, acceleration and its effects, the sense organs in relation to flight, and the standards of physical fitness required for flying conditions. ..."

\section{Total War and the Human Mind}

A Psychologist's Experiences in Occupied Holland. By Major A. M. Meerloo, M.D., F.R.S.M. Size: Cr. 8vo. (Recently published). Price: 5s. Publisher: George Allen \& Unwin, Ltd.

"This book by a Dutch psychologist and medical doctor, the author of several works on social psychology, has for its subject the effects of total war on the minds of men. Major Meerloo, having spent two years in Occupied Holland, was able to draw on his own experiences in discussing such themes as Mass Reaction to German Occupation, Hitler's Psychological Weapons, and the Psychology of Courage. The author gives an interesting account of the immediate effects of occupation, and the subsequent terror and disorganisation of daily life. ..."

\section{BOOK REVIEWS}

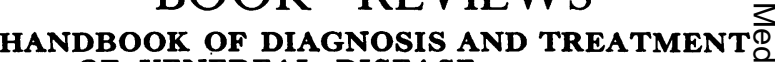
OF VENEREAL DISEASE

By A. E. W. McLachlan, M.B., Ch.B., D.P.H., F.R.S.(Edin.). Pp. 364,159 illustrations (I9 in colour). E. \& S. Livingstone, Edinburgh. 1944. Price I5s.

As the preface states, this handbook provides concise $\frac{C}{0}$ instruction for the elementary student and a profitable $\overline{\bar{n}}$. guide for the busy practitioner.

Venereal lesions, other conditions commonly mistaken $\mathbb{\Phi}_{\mathcal{D}}$ for them, their differential diagnosis, and the drugs usedo in treatment, are admirably catalogued, mostly in tabulares form. This important feature of the book, augmented $\vec{\circ}$ by carefully chosen, well-reproduced photographs, should:appeal especially to students taking their finals.

The chapter on the diagnosis of primary syphilis is parti- $\stackrel{\omega}{-}$ cularly valuable. The characteristics of chancres are esti=mably described, and their differential diagnosis is painstakingly set out in a large table. Another, giving. the chief positions in which they are found, shows that their commonest site of chancres in the female is on the cervix (40-50 per cent.). This simple anatomical fact enablesw the painless, symptomless, but deadly chancre to spread. its disastrous infection so unsuspectingly, that this little- $w$ known danger is one of the root causes of syphilitico
dissemination.

Although, as the author rightly states, "the end resultshave not as yet been fully evaluated," more than a meagrec page might have been given with advantage to the treat-J ment of early syphilis by massive arsenotherapy. Excellent results have,been obtained by the intensive five-day method mentioned, but the high mortality ( $\mathrm{I}$ in 450 ) is $\mathrm{I}$ reduced considerably ( $I$ in 3,000 ) by lengthening this perigd $\mathrm{d}_{A}$ to $20-25$ weeks. This compromise between the five-deycr course and the author's orthodox schedule of 59 we has produced very satisfactory results. Further progresso with arsenotherapy in the reduction of reactions and the time required for a cure may well be along these lines, but preliminary investigations suggest that then arsenicals may be discarded for the nontoxic and thera- $\frac{0}{\mathrm{D}}$ peutically more active penicillin. Its potent effect ono syphilis is being observed with great interest.

Five chapters are devoted to late generalised syphilis, lesions of bones, joints, muscles, viscera, and to cardiovascular and neuro-syphilis. Inevitably, however, these later sequelae are more fully described than their treatment, for this intricate aspect of syphilitic therapyo demands the resources of the consultant for each individual patient, and no handbook can deal adequately with? these complex cases.

The sulphonamides are recommended for chancroid: and as they have no effect on $S p$. pallida, their values in controlling chancroidal ulceration in cases of mixedB infections to facilitate discovery of the spirochaete is advisedly noted, for this advantage is often forgotten.

Chemotherapy as applied to gonorrhoea is described 7 together with the possible toxic reactions and the requisite precautions. But, before a cure with sulphonamides canbe determined, as these drugs tend to mask gonococcals infections, meticulous and prolonged pathological tests are essential. They are tabulated in the criteria of cure; mores might have been written on this crucial and difficultw subject.

This useful volume is an excellent compendium of th\& principles and practice of venereology: the modern methodso of diagnosis are concise, and the schemes of treatmen 5 are founded on sound, orthodox and well-tried experiences The author is to be congratulated on having provided $a$ much-needed text-book; it can be throughly recommended to all who are interested in this topical subject. 